
\title{
28 Research Soure \\ A case-control Study on Blood Lipid Profile in Patients with COVID-19
}

Shahab Changaripour

Kerman University of Medical Sciences

\section{Hosna Sarvazad}

Kermanshah University of Medical Sciences

\section{Maryam Barghi}

Shiraz University

\section{Elham Sajadi}

Shiraz University

\section{Mahdi Hashempour Sadeghian}

Kermanshah University of Medical Sciences

Narges Eskandari Roozbahani ( $\square$ neskandari32@gmail.com )

Kermanshah University of Medical Sciences https://orcid.org/0000-0003-2509-9177

\section{Research}

Keywords: COVID-19, Dyslipidemias, LDL-C, HDL-C, Odds Ratio

Posted Date: May 3rd, 2021

DOI: https://doi.org/10.21203/rs.3.rs-423471/v2

License: (c) (i) This work is licensed under a Creative Commons Attribution 4.0 International License. Read Full License 


\section{Abstract}

Background Dyslipidemia has been reported in patients with virus infections. This study was performed to evaluate the blood lipid profile in the patients with coronavirus disease 2019 (COVID-19), and exploring the underlying factors in its development and their predictive value for the severity of COVID-19.

Methods In a case-control study, the lipid profile of patients with COVID-19 at the first admitted to two clinical centers in the west of Iran (July 2020 to Dec. 2020) and age- and gender-matched healthy people were explored. Three groups of controls, patients with the severe form of Covid-19 (admitted to the intensive care unit (ICU)), patients with Covid-19 with less intensity (outpatient admission), were defined for the subjects included in the study. The predictive values of different variables obtained from medical records for COVID-19 severity were analyzed.

Results Generally, 48 outpatients and 49 ICU patients, including 70 men and 23 women with a mean age of $62.4 \pm 13.5$ years, were included in the study. The control group consisted of 32 people, match sex and age with the patient groups. The mean triglyceride (TG) in the Covid-19 groups was higher than the control group, but there was no significant difference between them. The mean cholesterol in the patient groups was lower than the control group $(p=0.001)$. The mean of low-density lipoprotein cholesterol (LDL$\mathrm{C})$, and high-density lipoprotein cholesterol (HDL-C) was significantly different in the patient groups; HDL$\mathrm{C}$ in the ICU group was more than outpatient, and LDL-C in the outpatient group was more than ICU $(P<0.05)$. LDL-C and HDL-C in the ICU group were less than the control group, but there was no statistically significant difference between the two mentioned groups. The frequency of diabetes and hypertension was higher in the ICU group than in the outpatient group $(P<0.001)$. Furthermore, LDL-C level was associated with disease severity (odds ratio (OR): 0.966, 95\% confidence interval (Cl): 0.944-0.989, $\mathrm{P}=0.004)$.

Conclusion Lipid profiles in Covid-19 patients have different faces from healthy individuals. In the severe form, the lipid status has a different profile from the less severe form of Covid-19 disease. LDL-C level can be used as an indicator to determine the severity of Covid-19 disease.

\section{Introduction}

Since the onset of the Covid-19 coronavirus pandemic worldwide (December 2019), various clinical studies including aging [1], D-Dimer [2], C-reactive Protein [1], albumin depletion [1], and a history of diabetes [3] have been reported as risk factors associated with disease severity. Previous studies have hypothesized that viruses affect cellular metabolism due to the high anabolic need of virus-infected cells. To produce a vision, the entire cell biosynthesis apparatus undergoes rearrangement, and this process usually causes major changes in cellular lipidome [4-6]. Viruses lack basic metabolic processes and depend on the host's metabolic machinery. Lipids are used in the basal structure and membranes of viruses. Viruses for replication, membrane fusion, envelop formation, endocytosis, and transformation relies on the lipid [7, 8]. Significant changes in low-density lipoprotein cholesterol (LDL-C), high-density 
lipoprotein cholesterol (HDL-C), and other lipid profiles have been observed during lung infections and inflammation [9]. Changes in lipid metabolism in patients with inflammatory conditions are associated with adverse clinical outcomes. It was suggested that SARS-CoV-2 can induce excessive and uncontrolled cytokine storms in patients with a critical condition, which is associated with disease severity and poor prognosis [10]. Increased cytokines may alter the lipid profile of patients with COVID-19 [11].

Dyslipidemia caused by COVID-19 has been greatly underestimated, therefore has been led to poor treatment choices in these patients. In this study, we evaluated the status of lipid profile in patients with COVID-19 who for the first time admitted to the two medical centers of Imam Reza and Golestan Kermanshah, Iran.

\section{Subjects And Methods}

\section{Study design and patient selection}

This case-control study was conducted in two clinical centers, approved by the local ethics board of Golestan and Imam Reza Hospitals, Medical University of Kermanshah. A total of 97 patients with COVID19, from July 2020 to Dec. 2020, with completed lipid profile (TG, total cholesterol (TC), LDL-C, and HDLC) in the electronic medical record at the time of admission to the hospital and before any treatment interventions, were included. Patients with confirmed COVID-19 were diagnosed based on a positive SARS-CoV-2 nucleic acid RT-PCR result, using specimens derived from sputum, throat swab, or nasopharynx swab. Then they were divided into two categories outpatient (as less severe covid-19) and inpatient (as severe covid-19).

General clinical characteristics, including gender, age, comorbidities were collected from the electronic medical record (EMR).

\section{Lipid profile measuring}

Lipid profile was measured using a biochemical auto-analyzer (Mndary, BS 420, China) according to the manufacturer's instructions (Biorexfars, Iran). Total cholesterol, TG, HDL-C, and LDL-C were measured using the cholesterol oxidase-p-aminophenazone (CHOD-PAP) method; the glycerol phosphate oxidase-paminophenazone (GPO-PAP) method; the direct-hydrogen peroxide method; and the direct-surfactant removal method, respectively. The lipid profile data included in this study were from the fasting blood samples on the first admission of patients.

\section{Statistical analysis}

The obtained data were statistically analyzed using SPSS 22 Statistical software. The results of qualitative variables were reported in frequency (percentage) and to compare these variables, the Chisquare and Fisher's exact tests were used.

Quantitative variables were reported as a mean \pm standard deviation (SD). The t-test and ANOVA were used to compare the means of independent groups. 
To determine the risk factor for disease severity, at first univariate logistic regression method was used, and then significant independent variables were entered into the multivariate regression model. The significance level in all tests was considered less than 0.05 .

\section{Results}

Generally, 48 outpatients and 49 ICU patients, including 70 men and 23 women with a mean age of 62.4 \pm 13.5 years, were included in the study. The control group consisted of 32 people, match sex and age with the patient groups (Table 1).

People with a history of diabetes, hypertension, cancer, an autoimmune disorder, and hypercholesterolemia (taking statins) were more in the ICU group than the outpatient group, but only in terms of the frequency of diabetes and hypertension, there was a statistically significant difference between the two groups of patients $(P<0.001)$ (Table 1$)$.

Of the total patients, $55(41.7 \%)$ cases died of Covid-19, of which $31.3 \%$ belonged to the outpatient group and $81.6 \%$ belonged to the ICU group (Table 1 ). There was a statistically significant difference between patient groups in terms of survival status $(p<0.001)$.

There was no statistically significant difference between the three groups in terms of mean TG $(P=$ 0.208). Although the mean TG in the ICU group was lower than the outpatient group, there was no significant difference between them. However, the lowest mean was related to the control group (130.3 \pm 29.7) and it decreased from the outpatient group, ICU, and control group, respectively (Table 2).

There was a statistically significant difference between the three groups in terms of mean cholesterol ( $p$ $=0.013$ ). The lowest mean was in the ICU group so that cholesterol levels of control, outpatient, and ICU were decreasing, respectively (Table 2). Although cholesterol was lower in the ICU group than in the outpatient group, there was no statistically significant difference between them $(p=0.735)$.

The mean LDL-C was significantly different in the three groups $(P<0.001)$. The mean of this factor decreased in the outpatient, control, and ICU groups, respectively. There was a statistically significant difference between the outpatient group and the ICU $(P<0.001)$.

The mean HDL-C was different in the three groups $(p=0.001)$. Although the mean HDL-C in the outpatient group was lower than the control group $(p=0.001)$, there was no significant difference between the two groups of patients (Table 2).

To determine the risk factor for the severity of Covid-19, univariate and multivariate logistic regression methods were used, the results of which are presented in Table 3. Based on univariate regression analysis, only LDL-C and HDL-C variables were considered as risk factors for Covid-19 (HDL-C: odds ratio (OR): 1.070, 95\% confidence interval (Cl): 1.001-1.143, P = 0.047; LDL-C: OR: 0.963, Cl: 0.941-0.986, P= $0.02)$, and in multivariate regression analysis, only LDL-C variable was recognized as a risk factor (OR: 0.966, Cl: 0.944-0.989, $\mathrm{P}=0.004)$. 


\section{Discussion}

In this study, we investigated the blood lipid profile in the patients with COVID-19 and explored the underlying factors in its development and their predictive value for the severity of COVID-19. This study was performed on patients who have not yet received treatment for Covid-19 disease. Previous studies suggested dyslipidemia in viral infections $[12,13]$ and COVID-19 as well $[14,15]$. Various studies have been performed on the role of cholesterol in pulmonary function. In this regard, the mechanism by which LDL-C is linked to the cholesterol of surfactant in the lungs of hamsters was investigated. LDL-C and HDL-C of the bloodstream were taken by the lungs through specific receptors, thereby inhibiting the local biosynthesis of pulmonary cholesterol [16]. Other observational studies on animal models have shown that HDL-C acts as the primary source of antioxidant vitamin E for alveolar epithelial cells of type II [17], causing surfactant production by type II cells and the growth of lung fibroblasts [18]. It was shown that, although cholesterol is essential for the function of type II alveolar cells, the pulmonary surfactant and pulmonary phospholipid in a high-cholesterol (2\%) diet impair surfactant function. Indeed, increased cholesterol in the diet has been shown to alter the synthesis, composition, and function of surfactants [19].

According to previous findings, dyslipidemia is common in Covid-19 patients. We found that blood levels of HDL-C and LDL-C in the severe and less severe forms of Covid-19 disease have different faces, so that the level of HDL-C, unlike LDL-C, is lower in the less severe form of the disease than in the severe form. However, only the LDL-C variable was recognized as a risk factor. Clinical data show that HDL-C concentration decreases immediately after infection and there is a significant relationship between decreased levels and poor prognosis in infectious diseases [20-22]. It is possible that due to passing the early course of the disease, in this study there was no decrease in HDL-C level in the severe form of the disease. About dyslipidemia in Covid-19 patients, some studies have reported a decrease in lipid profiles as the disease progresses [23, 24]. Contrary to our study, in studies by Li et al. and Wang et al., a decrease in HDL-C levels was observed in severe cases of the disease, and this factor was reported as a risk factor for disease severity $[23,25]$. However, some studies are consistent with our results and have reported decreased LDL-C levels as a risk factor for disease severity [26].

We also examined the relationship between comorbidities in the study population and disease severity. Among the factors such as diabetes, hypertension, history of hypercholesterolemia, cancer, autoimmune diseases, and DVT, which were recorded in the patients' clinical file, only the frequency of two variables of diabetes and hypertension in severe and less severe Covid-19 had significant differences but were not considered as a risk factor for disease severity. Recent studies on the risk factors associated with disease severity and poor prognosis support the belief that diabetes $[27,28]$ and hypertension $[29,30]$ are the most important risk factors for rapid progression and poor prognosis of Covid- 19 .

In our study, only $6.1 \%$ of the total population had a history of hyperlipidemia and taking statins (including lovastatin, atorvastatin, rosuvastatin, and simvastatin). However, these people, along with those with no previous history of hyperlipidemia, developed dyslipidemia following Covid-19. Following 
the outbreak of Covid-19, research has also been done on the effect of existing drugs on the virus, and articles have been published on the role of statins in relieving the symptoms of Covid-19 and other viral infections [31-33]. However, there is a dilemma as to what stage of the disease and in which group of COVID-19, statin therapy is beneficial, and what type and the dose of statin to be given [34]. Our study population with a history of hyperlipidemia and taking the Statins are not comparable to recent studies due to its small sample size. Therefore, to prove the role of statins in the Covid-19 disease, more detailed clinical trials with larger sample sizes are needed.

This study was performed in two medical centers dedicated to the admission of patients with Covid-19, and the study population was those who had not yet received treatment for their disease, so what was concluded from the effect of the disease on the lipid profile was without therapeutic intervention. In our clinical centers among Covid-19 patients, request the lipid profile test was not routine; on the other hand, due to the inclusion criteria, the sample size of the study was affected, and this was the limitation of our study.

\section{Conclusion}

Lipid profiles in Covid-19 patients have different faces from healthy individuals. In the severe form, the lipid status has a different profile from the less severe form of Covid-19 disease. LDL-C level can be used as an indicator to determine the severity of Covid-19 disease.

\section{Declarations}

Conflict of interest: The authors do not have any professional and financial interest.

Funding information: The authors received no financial support for the research, authorship, and/or publication of this article.

Consent to participate: Verbal informed consent was obtained before the interview.

Consent for publication: The participant has consented to the submission of the case report in the journal.

Availability of data and material: No additional data are available

\section{Author contributions}

Changaripour Sh Concepts, Design, Definition of intellectual content, Clinical studies, Manuscript review, Data acquisition; Sarvazad H Literature search, Data acquisition, Manuscript preparation, Manuscript review; Barghi M Literature search, Data acquisition, Manuscript preparation, Manuscript review; Sajadi E Literature search, Data acquisition, Manuscript preparation, Manuscript review; Hashempour Sadeghian M Literature search, Data acquisition, Statistical analysis, Manuscript preparation, Manuscript review; 
Eskandari Roozbahani N Concepts, Design, Literature search, Data acquisition, Data analysis, Manuscript preparation, Manuscript editing, Manuscript review

\section{Acknowledgment}

The authors are grateful to the Clinical Research Development Center of Imam Reza Hospital for their kindly assist and advice.

\section{References}

1. Liu W, Tao Z-W, Wang L, Yuan M-L, Liu K, Zhou L, Wei S, Deng Y, Liu J, Liu H-G, et al: Analysis of factors associated with disease outcomes in hospitalized patients with 2019 novel coronavirus disease. Chinese Medical Journal 2020, 133(9).

2. Zhou F, Yu T, Du R, Fan G, Liu Y, Liu Z, Xiang J, Wang Y, Song B, Gu X et al: Clinical course and risk factors for mortality of adult inpatients with COVID-19 in Wuhan, China: a retrospective cohort study. The Lancet 2020, 395(10229):1054-1062.

3. Caramelo F, Ferreira N, Oliveiros B: Estimation of risk factors for COVID-19 mortality-preliminary results. MedRxiv 2020.

4. Diamond DL, Syder AJ, Jacobs JM, Sorensen CM, Walters K-A, Proll SC, McDermott JE, Gritsenko MA, Zhang Q, Zhao R: Temporal proteome and lipidome profiles reveal hepatitis $\mathrm{C}$ virus-associated reprogramming of hepatocellular metabolism and bioenergetics. PLoS Pathog 2010, 6(1):e1000719.

5. Gualdoni GA, Mayer KA, Kapsch A-M, Kreuzberg K, Puck A, Kienzl P, Oberndorfer F, Frühwirth K, Winkler S, Blaas D: Rhinovirus induces an anabolic reprogramming in host cell metabolism essential for viral replication. Proceedings of the National Academy of Sciences 2018, 115(30):E7158-E7165.

6. Hsu N-Y, Innytska O, Belov G, Santiana M, Chen Y-H, Takvorian PM, Pau C, van der Schaar H, KaushikBasu N, Balla T: Viral reorganization of the secretory pathway generates distinct organelles for RNA replication. Cell 2010, 141(5):799-811.

7. Lorizate M, Kräusslich H-G: Role of lipids in virus replication. Cold Spring Harbor perspectives in biology 2011, 3(10):a004820.

8. Murillo A, Vera-Estrella R, Barkla BJ, Méndez E, Arias CF: Identification of host cell factors associated with astrovirus replication in Caco-2 cells. Journal of virology 2015, 89(20):10359-10370.

9. Filippas-Ntekouan S, Liberopoulos E, Elisaf M: Lipid testing in infectious diseases: possible role in diagnosis and prognosis. Infection 2017, 45(5):575-588.

10. McGonagle D, Sharif K, O'Regan A, Bridgewood C: The role of cytokines including interleukin-6 in COVID-19 induced pneumonia and macrophage activation syndrome-like disease. Autoimmunity reviews 2020, 19(6):102537.

11. Rajamäki K, Lappalainen J, Öörni K, Välimäki E, Matikainen S, Kovanen PT, Eklund KK: Cholesterol crystals activate the NLRP3 inflammasome in human macrophages: a novel link between cholesterol metabolism and inflammation. PloS one 2010, 5(7):e11765. 
12. Baker J, Ayenew W, Quick H, Hullsiek KH, Tracy R, Henry K, Duprez D, Neaton JD: High-Density Lipoprotein Particles and Markers of Inflammation and Thrombotic Activity in Patients with Untreated HIV Infection. The Journal of Infectious Diseases 2010, 201(2):285-292.

13. Lee W, Ahn JH, Park HH, Kim HN, Kim H, Yoo Y, Shin H, Hong KS, Jang JG, Park CG, et al: COVID-19activated SREBP2 disturbs cholesterol biosynthesis and leads to cytokine storm. Signal Transduction and Targeted Therapy 2020, 5(1):186.

14. Choi GJ, Kim HM, Kang H: The potential role of dyslipidemia in COVID-19 severity: an umbrella review of systematic reviews. Journal of Lipid and Atherosclerosis 2020, 9(3):435.

15. Yang $\mathrm{H}$, Hou H, Liang $\mathrm{X}$, Xu J, Wang Y: Lack of significant association between dyslipidemia and COVID-19 mortality. The Journal of Infection 2021.

16. Nistor A, Simionescu M: Uptake of low-density lipoproteins by the hamster lung: interactions with capillary endothelium. American Review of Respiratory Disease 1986, 134(5):1266-1272.

17. Kolleck I, Schlame M, Fechner H, Looman AC, Wissel H, Rüstow B: HDL is the major source of vitamin E for type II pneumocytes. Free Radical Biology and Medicine 1999, 27(7):882-890.

18. Pian MS, Dobbs LG: Lipoprotein-stimulated surfactant secretion in alveolar type II cells: mediation by heterotrimeric G proteins. American Journal of Physiology-Lung Cellular and Molecular Physiology 1997, 273(3): L634-L639.

19. McCrae KC, Weltman B, Alyward S, Shaw RA, Sowa MG, Unruh HW, Rand TG, Thliveris JA, Scott JE: The effect of elevated dietary cholesterol on pulmonary surfactant function in adolescent mice. Pediatr Pulmonol 2008, 43(5):426-434.

20. Chien J-Y, Jerng J-S, Yu C-J, Yang P-C: Low serum level of high-density lipoprotein cholesterol is a poor prognostic factor for severe sepsis. Critical care medicine 2005, 33(8):1688-1693.

21. Tanaka S, Couret D, Tran-Dinh A, Duranteau J, Montravers P, Schwendeman A, Meilhac O: Highdensity lipoproteins during sepsis: from bench to bedside. Critical Care 2020, 24:1-11.

22. Van Leeuwen HJ, Heezius EC, Dallinga GM, van Strijp JA, Verhoef J, van Kessel KP: Lipoprotein metabolism in patients with severe sepsis. Critical care medicine 2003, 31(5):1359-1366.

23. Li Y, Zhang Y, Dai M, Shen M, Zhang J, Cui Y, Liu B, Lin F, Chen L, Han D: Changes in lipid metabolism in patients with severe COVID-19. 2020.

24. Zhu Z, Yang Y, Fan L, Ye S, Lou K, Hua X, Huang Z, Shi Q, Gao G: A Preliminary Study on Blood Lipid Profile in Patients with COVID-19. 2020.

25. Wang G, Zhang Q, Zhao X, Dong H, Wu C, Wu F, Yu B, Lv J, Zhang S, Wu G: Low high-density lipoprotein level is correlated with the severity of COVID-19 patients: an observational study. Lipids in health and disease 2020, 19(1):1-7.

26. Wei X, Zeng W, Su J, Wan H, Yu X, Cao X, Tan W, Wang H: Hypolipidemia is associated with the severity of COVID-19. Journal of Clinical Lipidology 2020, 14(3):297-304.

27. Abdi A, Jalilian M, Sarbarzeh PA, Vlaisavljevic Z: Diabetes and COVID-19: A systematic review on the current evidence. Diabetes Research and Clinical Practice 2020, 166:108347. 
28. Guo W, Li M, Dong Y, Zhou H, Zhang Z, Tian C, Qin R, Wang H, Shen Y, Du K et al: Diabetes is a risk factor for the progression and prognosis of COVID-19. Diabetes/Metabolism Research and Reviews 2020, 36(7):e3319.

29. Wu C, Chen X, Cai Y, Zhou X, Xu S, Huang H, Zhang L, Zhou X, Du C, Zhang Y: Risk factors associated with acute respiratory distress syndrome and death in patients with coronavirus disease 2019 pneumonia in Wuhan, China. JAMA internal medicine 2020, 180(7):934-943.

30. Zhou F, Yu T, Du R, Fan G, Liu Y, Liu Z, Xiang J, Wang Y, Song B, Gu X: Clinical course and risk factors for mortality of adult inpatients with COVID-19 in Wuhan, China: a retrospective cohort study. The lancet 2020, 395(10229):1054-1062.

31. Castiglione V, Chiriacò M, Emdin M, Taddei S, Vergaro G: Statin therapy in COVID-19 infection. European Heart Journal - Cardiovascular Pharmacotherapy 2020, 6(4):258-259.

32. Grimaldi D, Durand A, Gleeson J, Taccone FS: Failure of statins in ARDS: the quest for the Holy Grail continues. Minerva anestesiologica 2016, 82(11):1230-1234.

33. Rossi R, Talarico M, Coppi F, Boriani G: Protective role of statins in COVID 19 patients: the importance of pharmacokinetic characteristics rather than the intensity of action. Internal and Emergency Medicine 2020, 15(8):1573-1576.

34. Lee KCH, Sewa DW, Phua GC: Potential role of statins in COVID-19. International Journal of Infectious Diseases 2020, 96:615-617.

\section{Tables}

Table 1 Clinical characteristics of patients with confirmed COVID-19 


\begin{tabular}{|c|c|c|c|c|c|}
\hline Variables & $\begin{array}{l}\text { Total } \\
(\mathrm{n}=132)\end{array}$ & $\begin{array}{l}\text { Outpatients } \\
\text { (less Sever } \\
\text { COVID-19) } \\
(n=48)\end{array}$ & $\begin{array}{l}\text { Inpatients ( } \\
\text { Sever COVID- } \\
\text { 19) }(\mathrm{n}=49)\end{array}$ & $\begin{array}{l}\text { Control } \\
(n=32)\end{array}$ & $\begin{array}{l}\text { P- } \\
\text { value* }\end{array}$ \\
\hline Age (years) & $62.4 \pm 13.5$ & $63 \pm 14.3$ & $65.3 \pm 14.33$ & $58.03 \pm 10.23$ & 0.052 \\
\hline Men (\%) & $\begin{array}{l}43 \\
(32.6 \%)\end{array}$ & $38(79.2 \%)$ & $32(65.3 \%)$ & $19(54.3 \%)$ & 0.308 \\
\hline \multicolumn{6}{|l|}{ Comorbidities } \\
\hline Diabetes & $\begin{array}{l}23 \\
(23.7 \%)\end{array}$ & $7(14.6 \%)$ & $16(32.7 \%)$ & 0 & $<0.001$ \\
\hline Hypertension & $\begin{array}{l}43 \\
(32.6 \%)\end{array}$ & $18(37.5 \%)$ & $25(52 \%)$ & 0 & $<0.001$ \\
\hline Cancer & $7(5.3 \%)$ & $2(4.2 \%)$ & $5(10.2 \%)$ & 0 & 0.436 \\
\hline DVT & $4(4.1 \%)$ & $2(4.2 \%)$ & $2(4.1 \%)$ & 0 & 0.561 \\
\hline Autoimmune disorder & $13(9.8 \%)$ & $4(8.3 \%)$ & $9(18.4 \%)$ & 0 & 0.147 \\
\hline $\begin{array}{l}\text { Hypercholesterolemia } \\
\text { Statins consuming }\end{array}$ & $8(6.1 \%)$ & $1(2.1 \%)$ & $7(14.3 \%)$ & 0 & 0.059 \\
\hline \multicolumn{6}{|l|}{ Survival } \\
\hline Alive & $\begin{array}{l}77 \\
(58.3 \%)\end{array}$ & $33(68.8 \%)$ & $9(18.4 \%)$ & $32(100 \%)$ & $<0.001$ \\
\hline Death & $\begin{array}{l}55 \\
(41.7 \%)\end{array}$ & $15(31.2 \%)$ & $40(81.6 \%)$ & 0 & \\
\hline
\end{tabular}

*between two patient groups

DVT: Deep vein thrombosis

Table 2 Lipid profile results of patients with confirmed COVID-19 


\begin{tabular}{|c|c|c|c|c|c|}
\hline \multicolumn{2}{|l|}{ variable } & Total $(n=132)$ & Mean & Standard Deviation & P-value \\
\hline \multirow[t]{4}{*}{ TG } & outpatient & 48 & 157.60 & 92.465 & \multirow[t]{4}{*}{0.208} \\
\hline & ICU & 49 & 149.59 & 63.897 & \\
\hline & control & 35 & 130.31 & 29.709 & \\
\hline & Total & 132 & 147.39 & 70.075 & \\
\hline \multirow[t]{4}{*}{ Cholesterol } & outpatient & 48 & 149.85 & 41.135 & \multirow[t]{4}{*}{0.013} \\
\hline & ICU & 49 & 145.00 & 28.518 & \\
\hline & control & 35 & 165.71 & 19.535 & \\
\hline & Total & 132 & 152.26 & 32.777 & \\
\hline \multirow[t]{4}{*}{ LDL-C } & outpatient & 48 & 69.65 & 28.394 & \multirow[t]{4}{*}{$<0.001$} \\
\hline & ICU & 49 & 52.16 & 17.500 & \\
\hline & control & 35 & 59.46 & 6.608 & \\
\hline & Total & 132 & 60.45 & 21.674 & \\
\hline \multirow[t]{4}{*}{ HDL-C } & outpatient & 48 & 34.06 & 7.332 & \multirow[t]{4}{*}{0.001} \\
\hline & ICU & 49 & 37.08 & 6.757 & \\
\hline & control & 35 & 39.63 & 4.531 & \\
\hline & Total & 132 & 36.66 & 6.800 & \\
\hline
\end{tabular}

TG: Triglyceride; LDL-C: low-density lipoprotein cholesterol; HDL-C: high-density lipoprotein cholesterol

Table 3 The risk factor for the severity of Covid-19 among lipid profile results of patients with confirmed COVID-19

\begin{tabular}{ccccccc}
\hline Variable & \multicolumn{3}{c}{ Univariate analysis } & \multicolumn{2}{c}{ Multivariate analysis } \\
\cline { 2 - 6 } & OR & CI 95\% for OR & p-value & OR & CI 95\% for OR & p-value \\
\hline TG & 0.999 & $0.994-1.004$ & 0.617 & & & \\
\hline Cholesterol & 0.996 & $0.985-1.008$ & 0.496 & & & 0.004 \\
\hline LDL-C & 0.963 & $0.941-0.986$ & 0.002 & 0.966 & $0.944-0.989$ & \\
\hline HDL-C & 1.070 & $1.001-1.143$ & 0.047 & & & \\
\hline
\end{tabular}


TG: Triglyceride; LDL-C: low-density lipoprotein cholesterol; HDL-C: high-density lipoprotein cholesterol 